\title{
Prospective and retrospective study of bronchoscopic electro cautarizartion versus argon plasma coagulation as a palliative management for patients with bronchogenic carcinoma
}

\begin{abstract}
One of the main Indications for therapeutic endoscopic treatment is palliation of advanced cancerous lesions. Which is mainly for the relief of dyspnea due to central airway obstruction, and the pre-operative evaluation should confirm that the lung beyond the obstruction is viable and that dyspnea is effectively related to the obstruction. ${ }^{1}$ In this study we recommend that the role of therapeutic bronchoscopy should be used by chest physicians as a safe and effective method in management of patients with central malignant airway obstruction.
\end{abstract}

\author{
Volume 2 Issue 5 - 2018 \\ Mohamed Torky,' AmgadAbd-Elraoof,' \\ MostafaRagab, ${ }^{2}$ Ayman Abd-Elzaherand \\ GhadaAtef ${ }^{\prime}$ \\ 'Respiratory medicine department, Tanta University Hospital, \\ Egypt \\ ${ }^{2}$ Respiratory medicine department, Zaqaziq University Hospital, \\ Egypt
}

Correspondence: Mohamed Torky, Assistant lecturer at respiratory medicine department, Tanta University Hospital, Egypt, Email mohamedtorky2008@gmail.com

Received: November 04, 2014 | Published: August 21, 2015

\section{Introduction}

Endo bronchial electro surgery is used to remove endo bronchial lesions in the trachea and bronchial tree, using either a rigid or a flexible bronchoscope. The thermal property of electric current is used to destroy tissue or coagulate bleeding sites.

Many terms are used to describe the use of heat for tissue destruction as: Electrosurgery, electrocautery, electrotherapy and surgical diathermy. We specifically use the term electrocautery (EC) to describe the electrosurgical effect that requires contact between probe and tissue for the conduction of electric current ionizes air resulting in tissue destruction or hemostasis or both. ${ }^{2}$

Argon plasma coagulation (APC) is a relatively recent electrosurgical method whereby there is argon gas ionization by an electric current to create a noncontact, homogeneous "bridge" for tissue coagulation or ablation. ${ }^{3}$ Both EC and APC are effective methods for tissue coagulation and ablation. ${ }^{4}$

The aim of the study is to compare between the two interventions (electrocautarization and argon plasma coagulation) as a palliative treatment for bronchogenic carcinoma by both clinical study and investigations including pulmonary function tests and radiological findings.

\section{Materials and methods}

This is a study was carried out in the Chest department at Tanta University Hospitals from May 2012 to December 2012 on 20 cases.

\section{Inclusion criteria}

To be eligible for the study, patients had to have: i. Endo bronchial tumor which its main component is endo luminal present in the proximal main or lobar bronchi and proved to be Non-Small Cell Lung Carcinoma (NSCLC) by histopathological examination of stage IIIA or IIIB according to the AJCC staging. ${ }^{5}$

ii. In good general health without clinically significant medical history.

iii. No prior chemotherapy or radiotherapy.

\section{Exclusion criteria}

i. Patients with respiratory or heart failure.

ii. Patients with renal or liver failure.

iii. Patients with bleeding disorders.

iv. Patients with past history of allergic disorders to anesthetic drugs.

v. Patients with grade I,II, IV of bronchogenic carcinoma.

Included patients were classified into 2 groups:

Group 1: Included 10 patients and they were managed by palliative electrocautery.

Group 2: Included 10 patients and they were managed by palliative Argon Plasma Coagulation.

The number of therapy sessions was ranged from one to four sessions (15-40minutes each), with one week interval between each session.

\section{Preoperative fasting6}

Solid food should be avoided for 8hours preoperatively to allow 
sufficient time for gastric emptying. But liquid ingestion could be allowed up to 2 hours preoperatively.

\section{Premedication 7}

Regular cardiovascular medication including antihypertensive drugs also respiratory medication should be continued until the day of intervention. Also intravenous atropine $0.5 \mathrm{mg}$ could be given immediately prior to the intervention.

\section{Monitoring7}

Intraoperative monitoring including pulse, oxygen saturation, electrocardiography, and intermittent noninvasive measurement of blood pressure.

\section{Anesthetic technique7}

For interventional flexible bronchoscopy we used intravenous anesthesia consisting of hypnotic "midazolam" and analgesia "fentanyl".

\section{Ventilatory support during fiber optic bronchoscopy8}

Ventilatory support was done by connector tube which has 3 ends, one connected to EndoTrachealTube and the second connected to mechanical ventilator and last end through which Fibreoptic Bronchoscope introduced.

\section{Follow up9}

i. Symptoms were recorded and scored before treatment then one week after treatment using the Speiser symptom score. ${ }^{10}$

ii. Chest radiograph was done 1 week after bronchoscopic session for evaluation of re-expansion of atelectasis and prognosis of post obestruction pneumonia.

iii. Pulmonary function tests and arterial blood gases were done 1 week after bronchoscopic session for prognosis of endo-bronchial obstruction (Figure 1-8).

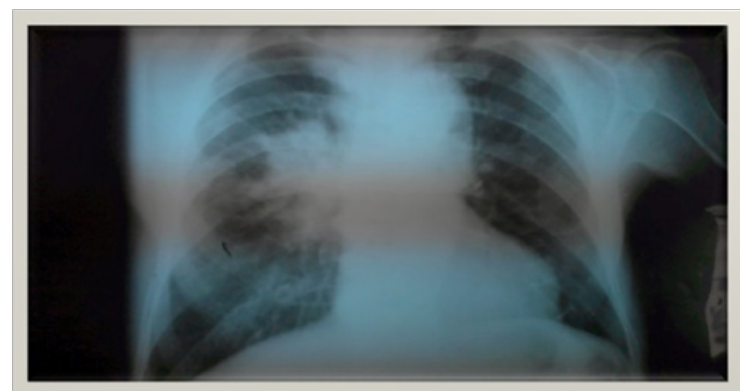

Figure I Showing a case with right central mass associated with post obstructive pneumonia.

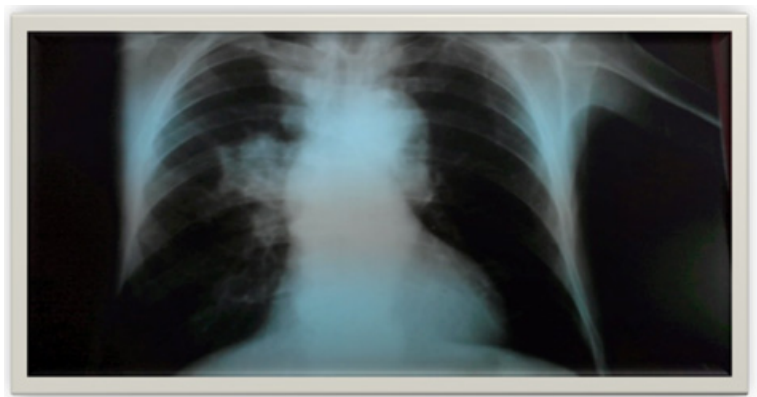

Figure 2 Showing reduction in the size of the mass with improvement in pneumonia after the application of electrocautery.

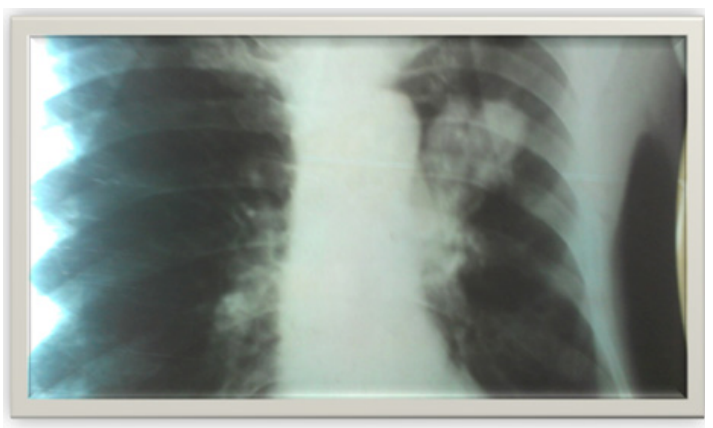

Figure 3 Show left apical mass.

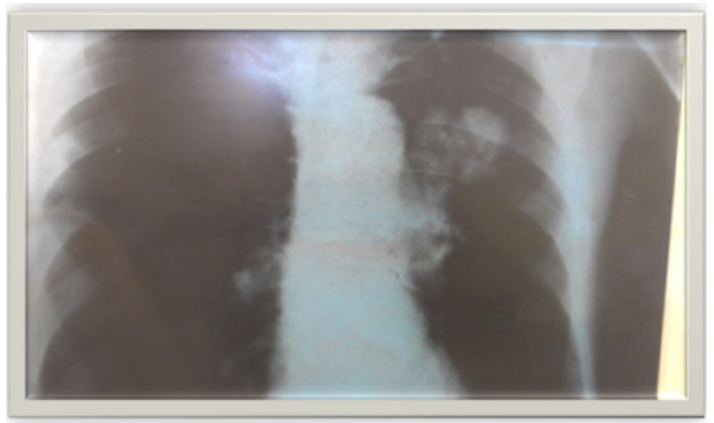

Figure 4 Show improvement after application of argon plasma coagulation

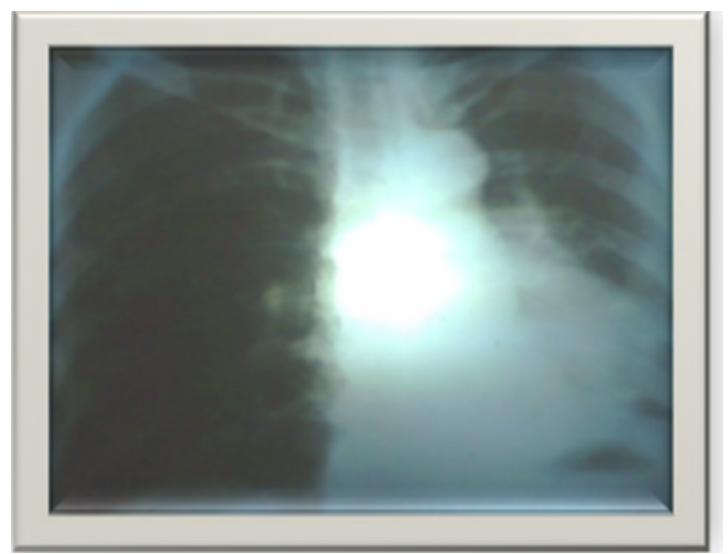

Figure 5 Show left lower mass with collapse.

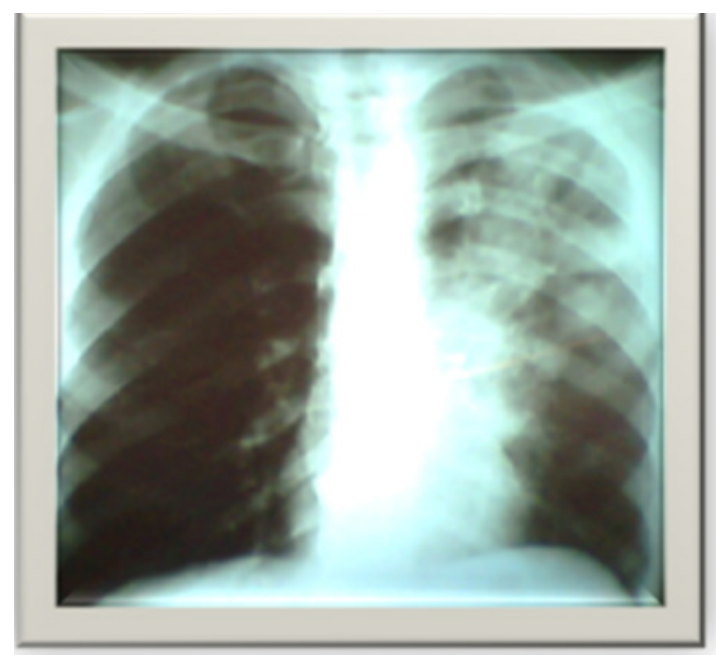

Figure 6 Show improvement after electrocautery.

Citation: Torky M, Elraoof A, Ragab M. Prospective and retrospective study of bronchoscopic electro cautarizartion versus argon plasma coagulation as a palliative management for patients with bronchogenic carcinoma.J Lung Pulm Respir Res. 20 I5;2(5):I I3-I I7. DOI: I0.I5406/jlprr.20I5.02.00059 


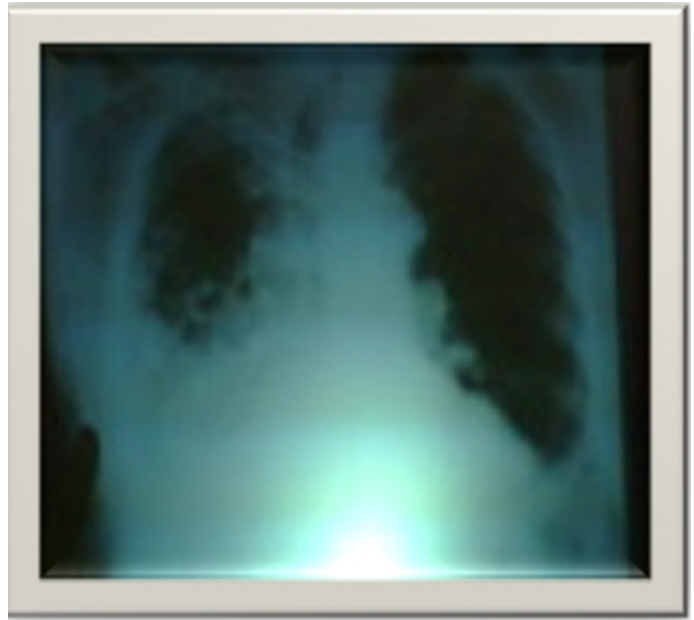

Figure 7 Show right lower mass with collapse.

\section{Clinical results}

Statistical presentation and analysis of the present study was conducted, using the mean, standard deviation and chi-square test by SPSS (statistical package for social sciences) V.16.

After application of bronchoscopic electrocautery on the included patients in group I. And argon plasma coagulation on the included patients in group II our study results showed that: There was a significant difference as regards control of heamoptysis between the 2 groups as group (II) show more control in heamoptysis than group (I). But there was no significant difference between the 2 groups as

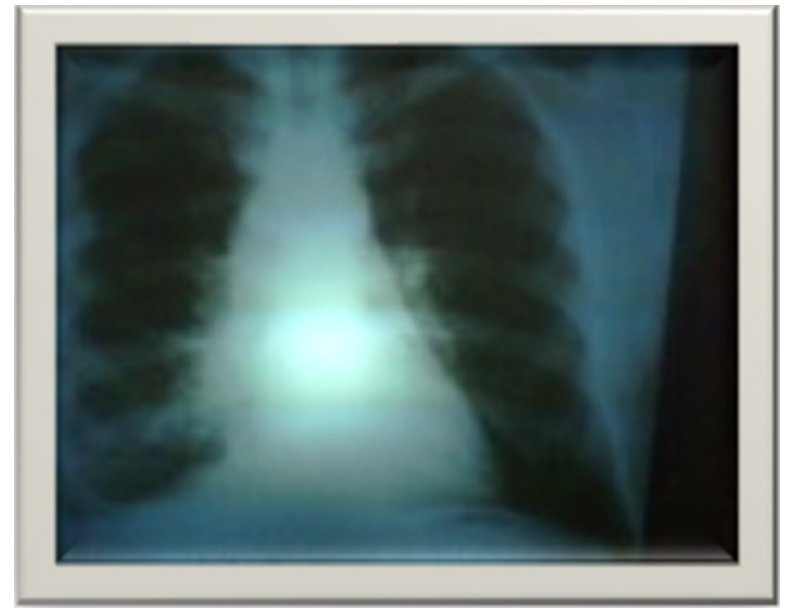

Figure 8 Show improvement after application of argon plasma coagulation.

regards improvement of other symptoms as cough, dyspnea and fever (Table1).

There was no significant difference in the comparison between the 2 groups as regards ventilatory function tests before bronchoscopic therapy and 1week after. But there was a significant difference in the results of each individual group as regards ventilatory function tests for its included patients before bronchoscopic therapy and 1week after (Table 2).

There was no significant difference between the 2 groups as regards post treatment complications (Table 3).

Table I comparison between the 2 groups according to symptoms before bronchoscopic therapy and I week after it

\begin{tabular}{|c|c|c|c|c|c|}
\hline \multirow[t]{2}{*}{ Symptoms } & \multicolumn{2}{|c|}{$\begin{array}{l}\text { Group (I) number of improved patients/patients } \\
\text { having symptoms No (\%) }\end{array}$} & \multicolumn{2}{|c|}{$\begin{array}{l}\text { Group (II) number of improved patients/patients } \\
\text { having symptoms No (\%) }\end{array}$} & \multirow[t]{2}{*}{ P value } \\
\hline & I week after & Before treatment & I week after & Before treatment & \\
\hline & 06-Oct & & 07-Oct & 10-Oct & \\
\hline \multirow[t]{3}{*}{ Cough } & & $10 / 10(100 \%)$ & & & 0.085 \\
\hline & $-60 \%$ & & $-70 \%$ & $-100 \%$ & \\
\hline & 05-Sep & 09-Oct & 06-Aug & $08-O c t$ & \\
\hline \multirow[t]{3}{*}{ Heamoptysis } & & & & & $0.048^{*}$ \\
\hline & $-55.50 \%$ & $-90 \%$ & $-75 \%$ & $-80 \%$ & \\
\hline & 06-Oct & $10-O c t$ & 07-Oct & I0-Oct & \\
\hline \multirow[t]{3}{*}{ Dyspnea } & & & & & 0.085 \\
\hline & $-60 \%$ & $-100 \%$ & $-70 \%$ & $-100 \%$ & \\
\hline & 05-Jul & 07-Oct & 04-Jun & 06-Oct & \\
\hline \multirow[t]{2}{*}{ Fever } & & & & & 0.057 \\
\hline & $-71.40 \%$ & $-70 \%$ & $-66.60 \%$ & $-60 \%$ & \\
\hline
\end{tabular}


Table 2 Comparison between the 2 groups according to ventilatory function tests before bronchoscopic therapy and I week after it

\begin{tabular}{|c|c|c|c|}
\hline Ventilatory- unction test & Group(I) & Group(II) & PValue \\
\hline \multicolumn{4}{|l|}{ FEV $1 \%$ Mean \pm SD } \\
\hline Pre-treatment & $45.9 \pm 11.9$ & $65.9 \pm 7.01$ & 0.051 \\
\hline I week-after & $60.5 \pm 11.24$ & $74.10 \pm 6.52$ & 0.068 \\
\hline$P$ value & $* 0.009$ & $0.003^{*}$ & \\
\hline \multicolumn{4}{|l|}{ FVC\%mean \pm SD } \\
\hline pre- treatment & $57.8+10.83$ & $72.4 \pm 5.52$ & 0.059 \\
\hline I week- after & $70 \pm 8.62$ & $79.10 \pm 5.28$ & 0.063 \\
\hline$P$ value & $0.002^{*}$ & $0.020^{*}$ & \\
\hline
\end{tabular}

Table 3 Comparison between the 2 groups according to post treatment complications

\begin{tabular}{llll}
\hline Complications No (\%) & Group(I) & Group(II) & P value \\
\hline No -complications & $8(80 \%)$ & $9(90 \%)$ & 0.966 \\
Heamoptysis & $\mathrm{I}(10 \%)$ & $\mathrm{I}(10 \%)$ & 0.999 \\
Pneumothorax & $\mathrm{I}(10 \%)$ & $0(0 \%)$ & \\
Esophegitis & $0(0 \%)$ & $0(0 \%)$ & \\
Pneumonia & $0(0 \%)$ & $0(0 \%)$ & \\
\hline
\end{tabular}

\section{Discussion}

When the airway obstruction is mainly endo luminal, endoscopic de bulking provides immediate and safe relief of symptoms. This may be achieved by various techniques including electrocautery and argon plasma coagulation. ${ }^{11}$ It is clear from the available data that electrocautery and argon plasma coagulation are effective and safe procedures as palliative therapy for endo bronchial obstruction. ${ }^{12}$ Morice et al., ${ }^{13}$ demonstrated that there was an immediate improvement in chest symptoms after tumor destruction in all patients. With marked improvement in dyspnea immediately after endo bronchial tumor de bulking in 37 cases (53\%). Kvale et al., ${ }^{14}$ showed immediate relief of dyspnea with electrocautery in 55 to $75 \%$ of patients. Sawang et al., ${ }^{15}$ reported that all the included patients showed significant improvement of symptoms including heamoptysis. Hossni et al., ${ }^{16}$ reported that improvement of pulmonary function tests (PFT) in the included patients after application of bronchoscopic electrocautery were FVC $15.8 \% \pm 6.6$ and FEV1 $12.6 \% \pm 4.9 .{ }^{16}$ Rajif et al., ${ }^{17}$ reported that most of included patients with central air way obstruction showed improvement after bronchoscopic electrocautery as regards clinical manifestations and pulmonary function tests. Crosta et al., ${ }^{11}$ demonstrated that no dangerous complications among the included patients have been observed. Sutedja et al., ${ }^{18}$ reported that no lethal complications related to the bronchoscopic electrocautery treatment and no episodes of respiratory failure.

\section{conclusion}

The role of therapeutic bronchoscopy should be kept in mind among chest physicians as a safe and effective method in management of patients with central malignant airway obstruction. Application of bronchoscopic techniques as electrocautery and argon plasma coagulation should be considered in other fields as benign airway obstruction and as a curative therapy in early malignant lesions.

\section{Acknowledgements}

None.

\section{Conflict of interest}

The author declares no conflict of interest.

\section{References}

1. Wahidi MM, Herth FJ, Ernst A. State of the art: interventional pulmonology. Chest. 2007;131(1):261-274.

2. Strand J, Maktabi M. The fiberoptic bronchoscope in emergent management of lower airway obstruction. Int Anesthesiol Clin. 2011;49(2):1519.

3. Grund KE, Storek D, Farin G. Endoscopic argon plasma coagulation (APC) first clinical experiences in flexible endoscopy. Endosc Surg Allied Technol. 1994;2(1):42-46.

4. Reichle G, Freitag L, Kullmann HJ, et al. Argon plasma coagulation in bronchology: a new method-alternative or complementary? Pneumologie. 2000;54(11):508-516.

5. Rami-Porta R, Crowley JJ, Goldstraw P. The revised TNM staging system for lung cancer. Ann Thorac Cardiovasc Surg. 2000;15(1):4-9.

6. Colt HG. Functional evaluation before and after interventional bronchoscopy. In: Progress Respiratory Research, Interventional Bronchoscopy. Prog Respir Res. Basel, Karger. 2000;30:55-64.

7. Studer W, Bolliger. CT Anesthesia for interventional bronchoscopy. In: Bolliger CT \& Mathur PN (Eds.), Interventional Bronchoscopy. Prog Respir Res. 2000;30:44-54. 
8. Jay B. Bronchoscopic procedures for central airway obstruction. Journal of Cardiothoracic and Vascular Anesthesia. 2003;17(5):638-646.

9. Mallick I, Sharma SC, Behera D. Endobronchial brachytherapy for symptom palliation in non-small cell lung cancer. analysis of symptom response, endoscopic improvement and quality of life. Lung Cancer. 2007;55(3):313-318.

10. Speiser B, Spratling L. Intermediate dose rate remote afterloading brachytherapy for intraluminal control of bronchogenic carcinoma. Int $J$ Radiat Oncol Biol Phys. 1990;18(6):1443-1448.

11. Crosta C, Spaggiari L, De Stefano A, et al. Endoscopic argon plasma coagulation for palliative treatment of malignant airway obstruction:early results in 47 cases. Lung Cancer. 2001;33(1):75-80.

12. Bolliger CT, Sutedja TG, Strausz J, et al. Therapeutic bronchoscopy with immediate effect: laser, electrocautery, argon plasma coagulation and stents. Eur Respir J. 2006;27(6):1258-1271.

13. Morice RC, Ece T, Ece F, et al. Endobronchial argon plasma coagulation for treatment of hemoptysis and neoplastic airway obstruction. Chest. 2001;119(3):781-787.
14. Kvale P.A, Simoff M, Udaya BS. Palliative Care. Chest. 2003;123(1):284-311.

15. Sawang S, Chana B, Narumol M, et al. SJ Med Assoc Thai. 2006;89(4):459-461.

16. Hosni H, Safwat T, Khattab A, et al. Interventional bronchoscopy: Egyptian. Journal of Bronchology. 2007.

17. Rajiv G, Pratibha G, Mohit G. Outcome after bronchoscopic electrocautery to relieve central airway obstruction for curative, facilitative and palliative purpose in a series of 55 patients. 2012.

18. Sutedja G, vanKralingen K, Schramel F. Fiberoptic bronchoscopy electrosurgery under local anesthesia for rapid Palliation in patients with central airway malignancies: a preliminary report. Thorax. $1994 ; 49(12): 1243-1246$ 